\title{
Outcomes in patients with severe sepsis or septic shock with a urinary source of infection in the ICU
}

\author{
ML Pérez Pérez , A Ortega López, A Pérez Lucendo, B Lobo Valbuena, N Martínez Sanz, J Palamidessi Domínguez, \\ R Fernandez Rivas, P Matía Almudevar, A Naharro Abellán, P Galdos Anuncibay
}

From ESICM LIVES 2015

Berlin, Germany. 3-7 October 2015

\section{Introduction}

Urinary tract infection (UTI) is a heterogeneous syndrome ranging from cystitis to bacteremia with shock and multiple organ failure.

\section{Objectives}

To assess the characteristics of patients admitted to the ICU with a main diagnosis of UTI complicated with severe sepsis or septic shock. We focused on relevant urologic history $(\mathrm{UH})$, radiological findings $(\mathrm{RF})$, need of urologic procedures, causative organisms, antimicrobial therapy (AT) and patients' outcomes in the ICU.

\section{Methods}

Retrospective observational study conducted in a medical ICU of a tertiary university hospital. Demographic data, model scores (APACHE, SOFA), UH, immunosuppression, RF, microorganisms, AT, number of organ failures (NOF), supportive care and overall mortality were recorded.

\section{Results}

Fifty four patients with a urinary source of infection were admitted to the ICU between May 2012 and March 2015. Mean age 61.1 \pm 13.6. Men 55.6\%. 11 immunosuppressed patients. Mean APACHE II 17.2 \pm 9.6. Mean SOFA $6.6 \pm 3.1$. First lactic acid $3.1 \pm 2.1$. Average length of stay $4.4 \pm 2.1$ days.

Fifty five point six of these patients had a previous UH: $22.2 \%$ needed Double J stents, $14.8 \%$ transrectal prostatic biopsy and $24.1 \%$ needed nephrostomy tubes or other procedures.

The main diagnosis on admission was acute pielonefritis (57.4\%); followed by sepsis related to transrectal prostatic

Hospital Universitario Puerta de Hierro Majadahonda, Madrid, Spain biopsy (14.8\%), complicated urinary tract infection (11.1\%) and prostatitis $(7.4 \%)$.

We found RF in $43.7 \%$. $27.4 \%$ needed urologic procedures during the ICU stay.

Antimicrobial resistance was detected among twenty two (40.7\%) of the isolated microorganisms. Escherichia coli was the predominant microorganism: 14 were resistant (R) to ciprofloxacin, $2 \mathrm{R}$ to cotrimoxazole and 4 presented extended-spectrum beta-lactamases. Carbapenems were used in $64.8 \%$ patients. After empiric antimicrobial therapy, we de-escalated in $66.7 \%$ of these patients, with no associated complications.

NOF were 1 or 2 in $74.1 \%$ : $70.4 \%$ needed vasoactive support, 4 patients required mechanical ventilation and 4 received continuous renal replacement therapy. 3 patients died (5.6\%).

Patients with UH needed more urologic procedures and had more NOF, but no statistically significant differences were found $\{$ RR 1.9, IC 95\% (0.5-6.5)\}, \{RR 2.5, IC 95\% (0.69-9)\}.

A statistical trend showed that patients with a higher number of RF required more urologic procedures, although with no statistical significance $\{$ RR 2.1, IC 95\% (0.6 - 7.3)\}. Furthermore, no statistical significance association was found between $\mathrm{UH}$ and bacterial resistance or immunosuppression.

\section{Conclusions}

Patients with severe sepsis or septic shock due to UTI in the ICU had a satisfactory outcome.

De-escalation was done in two thirds of the patients with no complications.

We found a high percent of patients with a previous urologic history and radiological findings who needed more urologic procedures but no statistically significant associations were found. 

sepsis or septic shock with a urinary source of infection in the ICU. Intensive Care Medicine Experimental 2015 3(Suppl 1):A84.

\section{Submit your manuscript to a SpringerOpen ${ }^{\circ}$ journal and benefit from:}

- Convenient online submission

- Rigorous peer review

- Immediate publication on acceptance

- Open access: articles freely available online

- High visibility within the field

- Retaining the copyright to your article

Submit your next manuscript at $\gg$ springeropen.com 